\title{
Human leukocyte antigen associations with renal function among ethnic minorities in the United Kingdom
}

DOI:

10.1111/tan.14078

\section{Document Version}

Accepted author manuscript

Link to publication record in Manchester Research Explorer

\section{Citation for published version (APA):}

Lowe, M., Payton, A., Verma, A., Gemmell, I., Worthington, J., Hamilton, P., Ollier, W., Augustine, T., \& Poulton, K. (2020). Human leukocyte antigen associations with renal function among ethnic minorities in the United Kingdom. HLA, 96(6), 697-708. https://doi.org/10.1111/tan.14078

\section{Published in:}

HLA

\section{Citing this paper}

Please note that where the full-text provided on Manchester Research Explorer is the Author Accepted Manuscript or Proof version this may differ from the final Published version. If citing, it is advised that you check and use the publisher's definitive version.

\section{General rights}

Copyright and moral rights for the publications made accessible in the Research Explorer are retained by the authors and/or other copyright owners and it is a condition of accessing publications that users recognise and abide by the legal requirements associated with these rights.

\section{Takedown policy}

If you believe that this document breaches copyright please refer to the University of Manchester's Takedown Procedures [http://man.ac.uk/04Y6Bo] or contact uml.scholarlycommunications@manchester.ac.uk providing relevant details, so we can investigate your claim.

\section{OPEN ACCESS}




\section{Title page}

\subsection{Title}

Human leukocyte antigen associations with renal function among ethnic minorities in the United Kingdom

\subsection{Short title}

HLA and renal function in UK BAME communities

\subsection{Authors}

Marcus Lowe ${ }^{1,3}$, Dr Antony Payton², Prof Arpana Verma ${ }^{3}$, Dr Isla Gemmell ${ }^{3}$, Dr Judith Worthington ${ }^{1}$, Dr Patrick Hamilton ${ }^{4}$, Prof William Ollier ${ }^{3,5}$, Prof Titus Augustine ${ }^{4,6}$, Prof Kay Poulton ${ }^{1,3}$

\subsection{Affiliations}

${ }^{1}$ Transplantation Laboratory, Manchester Royal Infirmary, Manchester University NHS Foundation Trust

${ }^{2}$ Division of Informatics, Imaging \& Data Sciences, School of Health Sciences, Faculty of Biology, Medicine and Health, University of Manchester

${ }^{3}$ Division of Population Health, Health Services Research and Primary Care, University of Manchester

${ }^{4}$ Department of Renal and Pancreas Transplantation, Manchester Royal Infirmary, Manchester University NHS Foundation Trust

${ }^{5}$ Centre for Bioscience, Faculty of Science and Engineering, Manchester Metropolitan University

${ }^{6}$ Division of Diabetes, Endocrinology and Gastroenterology, University of Manchester

\subsection{Corresponding author}

Marcus Lowe ${ }^{1,3}$ marcus.lowe@mft.nhs.uk +44 1612767920

\subsection{Keywords}

Kidney Failure, Chronic; Renal Insufficiency; Glomerular Filtration Rate; HLA Antigens; Genome-Wide Association Study; Polymorphism, Single Nucleotide; Imputation 


\section{Abstract}

\subsection{Background}

Human leukocyte antigens (HLA) have been independently associated with increased or decreased renal function. However, previous studies report contradictory findings with little consensus on the exact nature or impact of this observation. There has been a lack of research into how HLA affects renal function in Black, Asian and Minority Ethnic (BAME) people in the UK, despite the fact that BAME people are disproportionately affected by renal dysfunction.

\subsection{Methods}

This study included over 27,000 subjects of six different ethnicities $(>12,100$ Irish, $>5,400$ Indian, >4,000 Black Caribbean, >3,000 Black African, >1,600 Pakistani, and >1,400 Chinese) aged 39-73 when they were recruited by UK Biobank between 2006 and 2010. Subjects' high-resolution HLA genotypes were imputed using HLA*IMP:02 software. Regression analysis was used to compare a total of 110 imputed HLA alleles with two different measures of estimated glomerular filtration rate (eGFR), one based on serum creatinine and one based on serum cystatin. Secondary analysis of CKD stage 2 subjects (compared to healthy controls) was also performed.

\subsection{Results}

Eleven imputed HLA alleles were associated with eGFR $(P<0.001)$. Six of these associations were based on creatinine in Black African subjects: HLA-B*53:01 (beta=-2.628, $\mathrm{P}=8.38 \times 10^{-}$ $\left.{ }^{6}\right) ; C^{*} 04: 01$ (beta=-1.667, $\left.P=4.80 \times 10^{-4}\right) ; \quad D P A 1{ }^{*} 02: 01 \quad$ (beta=-1.569, $P=3.25 \times 10^{-4}$ ); and DPA1*02:02 (beta $=-1.716, P=4.49 \times 10^{-4}$ ) were linked to decreased renal function, while DRB1*03:01 (beta=3.200, $P=7.13 \times 10^{-5}$ ) and DPA1*01:03 (beta=2.276, $P=4.13 \times 10^{-7}$ ) were linked to increased renal function. Two of these alleles (HLA-B*53:01 and $\left.C^{*} 04: 01\right)$ are


and a lack of DRB4 genes (beta $=0.6193, P=8.62 \times 10^{-4}$ ) were linked to increased eGFR (based on cystatin); in Indian subjects, HLA-DRB1*03:01 (beta=-1.72, $P=8.69 \times 10^{-5}$ ), $\mathrm{DQB1}{ }^{*} 02: 01$ (beta $=-1.755, \mathrm{P}=4.11 \times 10^{-5}$ ), and a reduced frequency of DRB3 genes (beta=1.033, $P=4.88 \times 10^{-4}$ ) were associated with decreased eGFR (based on cystatin). No significant associations were found between $\mathrm{HLA}$ and renal function in any of the other three ethnic groups. 


\subsection{Conclusion}

Eleven HLA alleles appear to be associated with kidney function in people of BAME backgrounds in the UK. This could have important applications for the diagnosis and treatment of renal disease and could help reduce health inequalities in the UK. 


\section{Main text}

\subsection{Introduction}

Chronic kidney disease (CKD) is $17^{\text {th }}$ in the worldwide list of diseases which cause the most "years of lost life", according to the Global Burden of Disease 2015 study; it was $21^{\text {st }}$ in 2005 and $25^{\text {th }}$ in $1990^{1}$. The same study reported that CKD caused 1.2 million deaths in 2015 , an increase of $32 \%$ compared to 2005 . In developed countries, treatment for end-stage renal disease (ESRD) typically accounts for around $2-3 \%$ of the overall healthcare budget ${ }^{2}$. In England, CKD affects over 1.8 million people and over 40,000 people are on some form of renal replacement therapy (RRT, usually either dialysis or kidney transplantation) ${ }^{3}$.

Renal dysfunction is a problem that disproportionately affects Black, Asian and Minority Ethnic (BAME) people in the UK. Although BAME people represent only $11 \%$ of the UK population ${ }^{4}$, they accounted for $24 \%$ of patients dependent on renal replacement therapy in $2017^{5}$. BAME people are more likely to develop CKD than white people ${ }^{6}$, and those who have CKD experience faster decline in renal function than white people ${ }^{7}$. Understanding the genetic causes of renal dysfunction in BAME people in the UK could play an important role in reducing these health inequalities.

Heritability of CKD is thought to be between $30-75 \%^{8}$. The Human Leukocyte Antigen (HLA) system, encoded within the major histocompatibility complex, has been reported to be associated with renal function ${ }^{9}$. This may be because unique HLA alleles confer different levels of protection from different diseases associated with ${ }^{10}$ kidney dysfunction. Almost 100 HLA alleles and haplotypes have been linked to increased or decreased risk of renal failure ${ }^{11}$. However, conflicting associations have been reported, for example HLA-A*11 was linked to increased ESRD in a study of Azerbaijani subjects ${ }^{12}$ but protective against ESRD in a study of Turkish subjects ${ }^{13}$. This and other conflicting findings may be in part due to population stratification, as well as differing patterns of linkage disequilibrium (which lead to different combinations of genes among different ethnicities), and environmental effects.

This study uses a cohort of over 27,000 subjects aged $39-73$ who were recruited in the UK but do not identify as ethnically "British". The study aims to discover high-resolution HLA alleles which are associated with either increased or decreased renal function. Most previous studies used case-control methodology with a smaller number of subjects, usually all of a single ethnicity or nationality. Here we present the findings of a retrospective cohort study using subjects of six different ethnicities who are mostly healthy. 


\subsection{Methods}

\subsubsection{Quality control and identification of study population}

This study used data from UK Biobank (UKB) to test for associations between HLA and renal function in over 27,000 subjects from six different self-reported ethnic groups (Irish, Indian, Black Caribbean, Black African, Pakistani, and Chinese). UKB holds data on 502,616 subjects who were aged 39-73 when they were recruited in the UK between 2006-2010. 409,692 subjects $(81.5 \%)$ reported their ethnic background as "British" and genetic principal component analysis performed by UKB concurred; these subjects were analysed separately and the results reported elsewhere. The remaining 92,924 subjects (those who did not report their ethnic background to be "British", and those who self-identified as "British" but UKB's principal component analysis suggested were not British) were considered for this study.

714 individuals were removed during quality control. Of these: 129 had ambiguous genetic sex (a confounder in the calculation of subjects' kidney function); 420 were related to other subjects in the cohort (kinship coefficient $\geq 0.044$; the individual with the most complete set of genetic data was included); 132 were removed at UKB's recommendation due to "missing genetic data"; and 33 withdrew their consent to be included in the study. There were 92,210 subjects remaining after quality control.

As previous studies have suggested that HLA associations with renal function vary depending on ethnicity, subjects were analysed only within their ethnic groups. There were 23 different groups depending on subjects' answers to the question, "What is your ethnic background?" Only groups of 1,000 or more subjects were analysed in this study in order to reduce type I and type II errors. A minimum cohort size of 1000 unrelated individuals provides $94 \%$ power to detect a genetic effect size of $3 \%$, assuming a $5 \%$ minor allele frequency (minimum used in our analysis) and additive model. We used a significance threshold of $\mathrm{P}<7.4 \times 10^{-5}$ (correction for multiple testing). Furthermore, ethnic backgrounds which were unknown, mixed, or categorised as something "other" than the options provided (for example "any other white background") were excluded from the analysis due to possible heterogeneity. Finally, the subjects who self-reported as "British" but whom UKB deemed not to be British were also excluded. This left a total of six ethnic backgrounds to be analysed: Irish ( $\mathrm{N}=13,071)$; Indian ( $\mathrm{N}=5,919)$; Black Caribbean $(\mathrm{N}=4,488)$; Black African $(\mathrm{N}=3,386)$; Pakistani $(\mathrm{N}=1,822)$; and Chinese $(\mathrm{N}=1,563)$. Table 1 shows the 23 ethnic groups, the number of subjects in each group, and whether the group was included in the analysis (along with reasons for exclusion if applicable).

Table 1 


\subsubsection{HLA typing}

Subjects were HLA typed by UKB using single nucleotide polymorphism imputation. HLA IMP:02 software ${ }^{14}$ was used to impute the following HLA loci: HLA-A, B, C (Class I) and DPA1, DPB1, DQA1, DQB1, DRB1, DRB3, DRB4, DRB5 (Class II) at a level equivalent to high-resolution typing using eight reference datasets. 362 high-resolution HLA genotypes were imputed, though some were excluded due to their frequencies not being in HardyWeinberg equilibrium (HWE), $\mathrm{P}<0.00014$. Overall, 9 alleles were excluded from particular ethnic groups due to HWE analysis (1 Irish, 4 Indian, 1 Black Caribbean, 1 Black African, 2 Pakistani, and 0 Chinese). Only alleles with $>5 \%$ frequency were considered for analysis. There were a total of 110 alleles with $>5 \%$ frequency in at least one cohort ( 47 for Irish subjects, 58 Indian, 56 Black Caribbean, 57 Black African, 56 Pakistani, and 50 Chinese). Table 2 shows the alleles which had $>5 \%$ frequency in each ethnic group, as well as which alleles were excluded due to HWE analysis.

Table 2

\subsubsection{Measuring renal function}

Renal function was primarily measured using estimated glomerular filtration rate (eGFR), based on two biomarkers: creatinine and cystatin. High levels of these biomarkers in a subject's serum are a sign of decreased renal function, while low levels are a sign of increased renal function. Subjects with decreased renal function have lower eGFRs than those with normal or increased renal function. This study used the CKD-EPI method of calculating eGFR ${ }^{15}$, which adjusts for age, sex, and ethnicity. Two separate formulae were used: one based on creatinine, and one based on cystatin. 2,333 subjects were missing creatinine values (7.8\%) and 2,322 were missing cystatin values (7.7\%), and were excluded from the corresponding analyses. For both formulae, eGFR is measured in millilitres per minute and the unit of any eGFR value reported in this text is " $\mathrm{mL} / \mathrm{min} / 1.73 \mathrm{~m}^{2}$ ". eGFR $\geq 120 \mathrm{~mL} / \mathrm{min} / 1.73 \mathrm{~m}^{2}$ is considered healthy, with lower eGFRs being indicative of decreasing renal function. eGFR $<60$ is indicative of CKD stage 3 , while eGFR $<15 \mathrm{~mL} / \mathrm{min} / 1.73 \mathrm{~m}^{2}$ is indicative of CKD stage 5 (ESRD, requiring RRT). A table summarising eGFRs by ethnicity can be seen in the Results section.

Subjects were also sorted into categories based on their eGFR and secondary "case-control" analysis was performed. Subjects with eGFR (based on cystatin) $<90 \mathrm{~mL} / \mathrm{min} / 1.73 \mathrm{~m}^{2}$ (a "mild" decrease in renal function, indicative of at least CKD stage 2 when combined with evidence of kidney damage ${ }^{16}$ ) were compared to subjects with eGFR $\geq 90 \mathrm{~mL} / \mathrm{min} / 1.73 \mathrm{~m}^{2}$ ("normal or increased" renal function). 


\subsubsection{Regression analysis}

Linear regression analysis was used to test for associations between HLA alleles (the predictor variable) and eGFR (a continuous outcome variable). 188 subjects who had received RRT were excluded from this analysis, as their eGFR values may have suggested healthy renal function even though their native function was poor. The total number of subjects included in analysis of eGFR based on creatinine was: 12,140 Irish; 5,427 Indian; 4,068 Black Caribbean; 3,012 Black African; 1,649 Pakistani; and 1,432 Chinese (27,728 total). For analysis of eGFR based on cystatin, the number of subjects included was: 12,143 Irish; 5,428 Indian; 4,068 Black Caribbean; 3,017 Black African; 1,649 Pakistani; and 1,434 Chinese (27,739 total). Separate regression analyses were performed for each of the six ethnic groups and both eGFR formulae.

Logistic regression analysis was performed to test for HLA associations in subjects with eGFR (based on cystatin) $<90 \mathrm{~mL} / \mathrm{min} / 1.73 \mathrm{~m}^{2}$ versus controls with eGFR $\geq 90 \mathrm{~mL} / \mathrm{min} / 1.73 \mathrm{~m}^{2}$. After excluding subjects with missing eGFR and those who had received RRT, there were 12,752 cases and 14,987 controls (Irish: 5,964 cases and 6,179 controls; Indian: 3,199 cases and 2,229 controls; Black Caribbean: 1,406 cases and 2,662 controls; Black African: 951 cases and 2,066 controls; Pakistani: 905 cases and 744 controls; Chinese: 327 cases and 1,107 controls).

In all analyses, age and sex were included as covariates. Bonferroni correction thresholds were applied for each ethnic group based on the number of alleles analysed within that group. $P$ values for significance ranged from $P<0.00109(0.05 / 46$, Irish subjects) to $\mathrm{P}<0.00089$ (0.05/56, Black African subjects and Black Caribbean subjects). All analysis was performed using Plink software ${ }^{17}$.

\subsection{Results}

\subsection{1 eGFR values by ethnicity}

Table 3 summarises the eGFR values calculated, stratified by ethnicity. All calculated eGFR values are included, although some subjects were excluded from analysis due to receiving RRT.

Table 3

\subsubsection{Regression analysis}

After correction for multiple testing, eleven associations were found between HLA and renal function in UK ethnic minority groups. Six of these relate to Black African subjects: HLA$B^{\star}$ 53:01 (beta $\left.=-2.628, P=8.38 \times 10^{-6}\right) ; \quad C^{*} 04: 01$ (beta=-1.667, $P=4.80 \times 10^{-4}$ ); DPA1*02:01 
(beta=-1.569, $\left.\mathrm{P}=3.25 \times 10^{-4}\right)$; and DPA1*02:02 (beta=-1.716, $\mathrm{P}=4.49 \times 10^{-4}$ ) were linked to decreased eGFR (based on creatinine) in Black Africans, while DRB1*03:01 (beta=3.200, $\left.\mathrm{P}=7.13 \times 10^{-5}\right)$ and DPA1*01:03 (beta=2.276, $\mathrm{P}=4.13 \times 10^{-7}$ ) were linked to increased eGFR

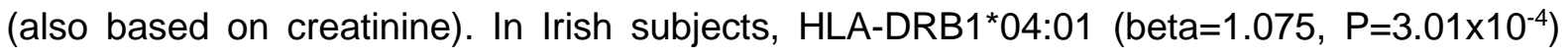
and a lack of DRB4 genes (beta $=0.6193, P=8.62 \times 10^{-4}$ ) were associated with increased eGFR (based on cystatin). HLA-DRB1*04:01 was also associated with decreased risk of CKD (stage 2 or worse) in Irish subjects (odds ratio=0.836, $P=1.77 \times 10^{-4}$ ). In Indian subjects, HLA-DRB1*03:01 (beta=-1.72, $P=8.69 \times 10^{-5}$ ), DQB1*02:01 (beta=-1.755, $P=4.11 \times 10^{-5}$ ), and a lack of DRB3 genes (beta=-1.033, $P=4.88 \times 10^{-4}$ ) were associated with decreased eGFR (based on cystatin). There were no significant associations found between HLA and eGFR for any of the other three ethnic groups (Black Caribbean, Pakistani, and Chinese). Table 4 shows all alleles significantly associated with eGFR. The table also shows the frequency of the allele within the ethnic group, the direction of the allele's association with kidney function (increase or decrease), which eGFR formula the allele was associated with (creatinine or cystatin), the beta value (the size and direction of the association with eGFR) and (if applicable) the odds ratio (size and direction of the association with CKD stage 2 or worse). Adjusted $P$ values of the associations are also provided.

Table 4

\subsection{Discussion}

The findings suggest that there may be HLA alleles which are associated with kidney function in BAME groups in the UK, especially Black Africans. Some findings replicated associations which had previously been reported. HLA-DRB1*03 has been found to be protective against $\lg A$ nephropathy in European people ${ }^{18}$; this study found that $D R B 1{ }^{*} 03: 01$ was linked to increased renal function in Black African subjects. On the other hand, the same gene has been reported to be linked to increased risk of kidney dysfunction in Taiwanese ${ }^{19}$, Saudi Arabian ${ }^{20}$, Turkish ${ }^{13}$, and Brazilian ${ }^{21}$ subjects. This study also found that HLA-DRB1*03:01 is linked to decreased kidney function in Indian subjects. Similarly, HLADRB1*04:01 has been linked to increased renal function in a study of Mexican subjects ${ }^{22}$, but decreased renal function in two Chinese studies ${ }^{23,24}$ and one German study ${ }^{25}$. This study found HLA-DRB1*04:01 to be associated with increased kidney function in Irish subjects. HLA-DRB $1{ }^{*} 03: 01$ and DRB1*04:01, therefore, appear to have complex interactions with kidney function which may differ depending on ethnicity. Furthermore, our observation that HLA-B ${ }^{\star} 53: 01$ is linked to decreased kidney function in Black Africans replicated the findings of a study of Venezuelan subjects, for whom the allele was associated with increased $\mathrm{ESRD}^{26}$. Finally, our finding that $\mathrm{HLA}-\mathrm{DQB} 1{ }^{*} 02: 01$ was linked to decreased kidney function 
in Indians replicated a study of Chinese subjects, for whom the gene was associated with increased renal failure ${ }^{27}$.

Two of the alleles linked to decreased kidney function in Black African subjects (HLA$B^{\star} 53: 01$ and $\left.C^{\star} 04: 01\right)$ form a common (9.2\% frequency) haplotype in African Americans ${ }^{28}$. This suggests that the genes may not be independently associated with renal function, but represent an associated haplotype. HLA-C*04:01 was analysed in every ethnic group except Chinese in this study but was only significant in the analysis of Black Africans. This may suggest that the gene itself does not contribute to decreased kidney function, but its apparent association is a result of its strong linkage disequilibrium with HLA-B*53:01. Alternatively, it may be associated with renal function in other ethnicities but this association may not have been detected due to lower frequency (and therefore reduced power) in nonBlack cohorts. The other genes associated with renal function in Black African subjects do not appear to be part of well-documented haplotypes.

Six of the eleven significant associations relate to creatinine in Black African subjects. A possible reason for this may be that creatinine levels are partially dependent on muscle mass and are therefore affected by ethnicity ${ }^{15}$. This may particularly affect estimates of GFR for Black subjects, who have higher muscle mass than other ethnic groups on average ${ }^{29}$. The CKD-EPI formula does adjust for ethnicity, but it is possible that this adjustment is not adequate, which could lead to false positive findings when analysing Black subjects.

The different populations showed different allele frequencies. 110 different alleles had $>5 \%$ frequency in at least one ethnic group, but only 17 had $>5 \%$ frequency in all six groups. As allele frequencies were so different among the different ethnic groups, it was essential to analyse ethnic groups separately in this study. The differing HLA frequencies across different populations may explain why renal dysfunction is more prevalent in some ethnic groups than others. However, Black African and Black Caribbean cohorts showed similar frequencies for many alleles, but none of the findings were replicated across the two groups. This is typical of association studies between HLA and renal function; findings are often not replicated even among apparently similar cohorts, possibly due to environmental differences or other genetic factors.

\subsubsection{Implications}

These findings suggest that, even within a broadly healthy population of people, HLA alleles may have an impact on renal function. Absolute effect sizes range from $0.62 \mathrm{~mL} / \mathrm{min} / 1.73 \mathrm{~m}^{2}$ to $3.20 \mathrm{~mL} / \mathrm{min} / 1.73 \mathrm{~m}^{2}$. One finding (HLA-DRB1*04:01 being linked to increased eGFR in Irish subjects) was replicated in the secondary analysis of clinical outcomes (the gene was linked to decreased risk of CKD stage 2 or worse); this suggests that small beta values are 
not a contraindication of clinical relevance. HLA typing may, therefore, help predict which people are at increased or decreased risk of developing adverse clinical outcomes. HLA association typing is already used to help diagnose a number of diseases ${ }^{30-32}$; it may be possible to use the findings of this study to help identify patients at risk of developing renal dysfunction and provide them with accelerated clinical pathways. It may particularly be of importance in combination with other concomitant clinical conditions like diabetes and hypertension which have a direct impact on kidney function. Likewise, it may be possible to use this data to reassure potential kidney donors with very good and stable renal function about long-term renal function. However, the findings are limited and additional research is required before these changes could be enacted.

\subsubsection{Strengths and weaknesses}

A strength of this study is that the primary outcome measure, eGFR, is an accurate and precise way to measure kidney function. Renal function is a continuous spectrum, and eGFR reflects this. Previous studies, which often used binary categorisations such as "ESRD or healthy", sacrificed precision by using these broad categories. The CKD-EPI method is particularly accurate when assessing renal function in healthy individuals ${ }^{33}$, so was the most appropriate formula for this study. Another strength of this study may be the size of the study groups (ranging from $>1,400$ Chinese subjects to $>12,000$ Irish), which are larger than many previous studies which have attempted to find associations between HLA and renal function. However, most previous studies used a case-control methodology, rather than a retrospective cohort methodology, so it is difficult to directly compare sample sizes. The adjustment for multiple testing applied in this study was stringent, with low $\mathrm{P}$ values required for results to be declared significant. For this reason, significant results are less likely to include type I errors. Age and sex were adjusted as covariates, which further reduces the chance of type I errors.

A limitation of this study is the HLA typing method (imputation), which is not as accurate as direct genotyping ${ }^{34}$. The reason that imputation was used is that it is more cost-effective than laboratory-based typing, which would have been prohibitively expensive. The imputation program used by UKB, HLA*IMP:02, was reported to be only $62 \%$ accurate when imputing African American subjects. The same study found another HLA imputation program, SNP2HLA, to be $92 \%$ accurate ${ }^{34}$. However, only nine alleles were not in HWE for particular ethnic groups (while 2,163 were in HWE, 99.6\%), demonstrating that the frequencies of alleles were consistent with expected frequencies. This contributed to an increased confidence in HLA assignment. 
Although this study includes six different ethnic groups (whereas most of the existing literature focuses on only a single ethnicity), there were many ethnic groups excluded from the analysis. Repeating the testing with more ethnicities may lead to further discoveries, since it appears that HLA associations with renal function vary according to ethnic background. The study also used self-reported ethnicity, which may be less accurate than evaluations of ethnicity based on more thorough genetic analysis. The UKB dataset may also not be representative of the respective populations. This would limit the extent to which findings can be applied to the populations as wholes. Finally, although study groups were relatively large, the lack of significant findings suggests that larger samples may be required in order to reliably detect associations, particularly if the associations are small.

\subsection{Conclusion}

This study identified eleven HLA associations with eGFR in people from BAME backgrounds in the UK. Six of these relate to Black African, three to Indian and two to Irish populations. One finding was replicated in the secondary analysis of clinical outcomes. No associations were found for any of the other three ethnicities studied. All of the alleles studied were in HWE and were present in $>5 \%$ of the relevant population. It is possible that there are further $\mathrm{HLA}$ associations with renal function but this study's cohort may not have been large enough to detect these; future analysis with larger study groups and a broader range of ethnicities may reveal additional associations. 


\section{Acknowledgements}

Data was provided by UK Biobank. Funding was provided by Kidneys for Life.

The authors declare no conflicts of interests.

Data cannot be shared as access is restricted to individuals named on the application to UK Biobank. 


\section{References}

1. Mortality GBD, Causes of Death C. Global, regional, and national life expectancy, all-cause mortality, and cause-specific mortality for 249 causes of death, 1980-2015: a systematic analysis for the Global Burden of Disease Study 2015. Lancet. 2016;388(10053):1459-1544.

2. Luyckx VA, Tonelli M, Stanifer JW. The global burden of kidney disease and the sustainable development goals. Bull World Health Organ. 2018;96(6):414-422D.

3. NHS. Chronic Kidney Disease in England: The Human and Financial Cost. 2012.

4. NHS. Organ Donation and Transplantation data for Black, Asian and Minority Ethnic (BAME) communities. 2019; https://nhsbtdbe.blob.core.windows.net/umbraco-assetscorp/17496/organ-donation-and-transplantation-bame-activityreport-2018-2019.pdf. Accessed 12 Mar, 2020.

5. UK Renal Registry. UK Renal Registry 21st Annual Report. 2019; https://www.renalreg.org/wpcontent/uploads/2019/05/21st UKRR Annual Report.pdf Accessed 2 June, 2020.

6. Dreyer G, Hull S, Aitken Z, Chesser A, Yaqoob MM. The effect of ethnicity on the prevalence of diabetes and associated chronic kidney disease. QJM. 2009;102(4):261-269.

7. Mathur R, Dreyer G, Yaqoob MM, Hull SA. Ethnic differences in the progression of chronic kidney disease and risk of death in a UK diabetic population: an observational cohort study. BMJ Open. 2018;8(3):e020145.

8. Canadas-Garre M, Anderson K, Cappa R, et al. Genetic Susceptibility to Chronic Kidney Disease - Some More Pieces for the Heritability Puzzle. Front Genet. 2019;10:453.

9. Robson KJ, Ooi JD, Holdsworth SR, Rossjohn J, Kitching AR. HLA and kidney disease: from associations to mechanisms. Nature reviews Nephrology. 2018;14(10):636-655.

10. Crux NB, Elahi S. Human Leukocyte Antigen (HLA) and Immune Regulation: How Do Classical and Non-Classical HLA Alleles Modulate Immune Response to Human Immunodeficiency Virus and Hepatitis C Virus Infections? Front Immunol. 2017;8:832.

11. Xu X, Eales JM, Akbarov A, et al. Molecular insights into genomewide association studies of chronic kidney disease-defining traits. Nat Commun. 2018;9(1):4800. 
12. Davood PP, Farhadi N, Najafizadeh M. Protective and susceptible HLA class I genes in patients with end-stage renal disease. Research Journal of Biological Sciences. 2008;3(11):1344-1346.

13. Karahan GE, Seyhun Y, Oguz FS, et al. Impact of HLA on the underlying primary diseases in Turkish patients with end-stage renal disease. Renal failure. 2009;31(1):44-49.

14. Bycroft C, Freeman C, Petkova D, et al. The UK Biobank resource with deep phenotyping and genomic data. Nature. 2018;562(7726):203-209.

15. Inker LA, Schmid $\mathrm{CH}$, Tighiouart $\mathrm{H}$, et al. Estimating glomerular filtration rate from serum creatinine and cystatin C. $N$ Engl J Med. 2012;367(1):20-29.

16. Levey AS, Eckardt KU, Tsukamoto $Y$, et al. Definition and classification of chronic kidney disease: a position statement from Kidney Disease: Improving Global Outcomes (KDIGO). Kidney Int. 2005;67(6):2089-2100.

17. Purcell S, Neale B, Todd-Brown K, et al. PLINK: a tool set for whole-genome association and population-based linkage analyses. Am J Hum Genet. 2007;81(3):559-575.

18. Doxiadis II, De Lange P, De Vries E, Persijn GG, Claas FH. Protective and susceptible HLA polymorphisms in IgA nephropathy patients with end-stage renal failure. Tissue antigens. 2001;57(4):344-347.

19. Dai CS, Chu CC, Chen SF, Sun CY, Lin M, Lee CC. Association between human leucocyte antigen subtypes and risk of end stage renal disease in Taiwanese: $A$ retrospective study. BMC Nephrology. 2015;16(1):177.

20. Hamdi NM, Al-Hababi FH, Eid AE. HLA class I and class II associations with ESRD in Saudi Arabian population. PloS one. 2014;9(11):e111403.

21. Yamakawa RH, Saito PK, da Silva Junior WV, de Mattos LC, Borelli SD. Polymorphism of leukocyte and erythrocyte antigens in chronic kidney disease patients in southern Brazil. PloS one. 2014;9(1):e84456.

22. Perez-Luque E, Malacara JM, Olivo-Diaz A, et al. Contribution of HLA class II genes to end stage renal disease in Mexican patients with type 2 diabetes mellitus. Human Immunology. 2000;61(10):1031-1038.

23. Cao Q, Xie D, Liu J, et al. HLA polymorphism and susceptibility to end-stage renal disease in Cantonese patients awaiting kidney transplantation. PloS one. 2014;9(6):e90869.

24. Chang DY, Luo H, Zhou X, Chen M, Zhao MH. Association of HLA genes with clinical outcomes of ANCA-associated vasculitis. 
Clinical Journal of the American Society of Nephrology. 2012;7(8):1293-1299.

25. Gencik M, Borgmann S, Zahn R, et al. Immunogenetic risk factors for anti-neutrophil cytoplasmic antibody (ANCA)-associated systemic vasculitis. Clinical and Experimental Immunology. 1999;117(2):412-417.

26. Rivera PS, Marquez G, Cipriani AM, et al. HLA class i association with progression to end-stage renal disease in patients from Zulia, Venezuela. Inmunologia. 2012;31(2):37-42.

27. Liu H, Wang B, Liu D, et al. Molecular genetic studies on relationships among longevity, diseases, and HLA-DRB1/DQB1 allelic polymorphism. Experimental aging research. 2007;33(2):123-125.

28. Allele Frequencies. USA African American pop 4. 2006; http://www.allelefrequencies.net/pop6001c.asp?pop id=2419.

Accessed 12 Mar, 2020.

29. Udler MS, Nadkarni GN, Belbin G, et al. Effect of Genetic African Ancestry on eGFR and Kidney Disease. J Am Soc Nephrol. 2015;26(7):1682-1692.

30. Kaukinen K, Partanen J, Maki M, Collin P. HLA-DQ typing in the diagnosis of celiac disease. Am J Gastroenterol. 2002;97(3):695699.

31. Sheridan DP, Lane PR, Irvine J, Martel MJ, Hogan DJ. HLA typing in actinic prurigo. J Am Acad Dermatol. 1990;22(6 Pt 1):10191023.

32. Chen B, Li J, He C, et al. Role of HLA-B27 in the pathogenesis of ankylosing spondylitis (Review). Mol Med Rep. 2017;15(4):19431951.

33. Florkowski CM, Chew-Harris JS. Methods of Estimating GFR Different Equations Including CKD-EPI. Clin Biochem Rev. 2011;32(2):75-79.

34. Karnes JH, Shaffer CM, Bastarache L, et al. Comparison of HLA allelic imputation programs. PLoS One. 2017;12(2):e0172444. 


\section{Tables}

Table 1: Subjects by self-reported ethnic background

\begin{tabular}{|c|c|c|c|}
\hline $\begin{array}{l}\text { Self-reported } \\
\text { ethnic group }\end{array}$ & $\begin{array}{l}\text { Self-reported ethnic } \\
\text { background }\end{array}$ & $\mathrm{N}$ & $\begin{array}{l}\text { Included } \\
\text { in analysis }\end{array}$ \\
\hline \multirow[t]{4}{*}{ White } & Prefer not to answer & 567 & $\mathrm{No}^{\dagger}$ \\
\hline & British & 32,662 & $\mathrm{No}^{\ddagger}$ \\
\hline & Irish & 13,071 & Yes \\
\hline & Any other white background & 16,252 & $\mathrm{No}^{*}$ \\
\hline \multirow[t]{5}{*}{ Mixed } & Prefer not to answer & 48 & $\mathrm{No}^{* \dagger}$ \\
\hline & White and Black Caribbean & 619 & $\mathrm{No}^{* \dagger}$ \\
\hline & White and Black African & 423 & $\mathrm{No}^{* \dagger}$ \\
\hline & White and Asian & 831 & $\mathrm{No}^{* \dagger}$ \\
\hline & Any other mixed background & 1,029 & $\mathrm{No}^{*}$ \\
\hline \multirow{5}{*}{$\begin{array}{l}\text { Asian or } \\
\text { Asian British }\end{array}$} & Prefer not to answer & 42 & $\mathrm{No}^{\dagger}$ \\
\hline & Indian & 5,919 & Yes \\
\hline & Pakistani & 1,822 & Yes \\
\hline & Bangladeshi & 236 & $\mathrm{No}^{+}$ \\
\hline & Any other Asian background & 1,809 & $\mathrm{No}^{*}$ \\
\hline \multirow{4}{*}{$\begin{array}{l}\text { Black or } \\
\text { Black British }\end{array}$} & Prefer not to answer & 27 & $\mathrm{No}^{\dagger}$ \\
\hline & Caribbean & 4,488 & Yes \\
\hline & African & 3,386 & Yes \\
\hline & Any other Black background & 123 & $\mathrm{No}^{* \dagger}$ \\
\hline \multicolumn{2}{|l|}{ Chinese } & 1,563 & Yes \\
\hline \multicolumn{2}{|c|}{ Prefer not to answer } & 1,651 & $\mathrm{No}^{*}$ \\
\hline \multicolumn{2}{|c|}{ Do not know } & 216 & $\mathrm{No}^{* \dagger}$ \\
\hline \multicolumn{2}{|c|}{ Other ethnic group } & 4,537 & $\mathrm{No}^{*}$ \\
\hline \multicolumn{2}{|c|}{ Data missing } & 889 & $\mathrm{No}^{* \dagger}$ \\
\hline \multicolumn{2}{|l|}{ Total } & 92,210 & \\
\hline \multicolumn{4}{|c|}{$\begin{array}{l}\text { *Excluded as ethnic group was mixed or "other" or miss } \\
\text { †Excluded as group size was less than } 1,000 \\
\text { †Excluded as these subiects self-reported their ethnic b }\end{array}$} \\
\hline
\end{tabular}

Table 2: HLA alleles by ethnicity with $>5 \%$ frequency and HLA alleles excluded due to HWE analysis

\begin{tabular}{|l|l|l|l|l|l|l|}
\hline HLA- & Irish & Indian & $\begin{array}{l}\text { Black } \\
\text { Caribbean }\end{array}$ & $\begin{array}{l}\text { Black } \\
\text { African }\end{array}$ & Pakistani & Chinese \\
\hline$A^{*} 01: 01$ & $23.1 \%$ & $15.2 \%$ & - & - & $15.9 \%$ & - \\
\hline$A^{*} 11: 01$ & $6.9 \%$ & $13.4 \%$ & - & - & $13.3 \%$ & $24.0 \%$ \\
\hline$A^{*} 11: 02$ & - & - & - & - & $-\dagger$ & - \\
\hline$A^{*} 02: 01$ & $25.9 \%$ & $5.2 \%$ & $10.6 \%$ & $9.4 \%$ & $5.8 \%$ & $8.7 \%$ \\
\hline$A^{*} 02: 02$ & - & - & - & $5.1 \%$ & - & - \\
\hline$A^{*} 02: 07$ & - & - & - & - & - & $8.6 \%$ \\
\hline$A^{*} 23: 01$ & - & - & $11.3 \%$ & $10.7 \%$ & - & - \\
\hline$A^{\star} 24: 02$ & $6.3 \%$ & $11.6 \%$ & - & - & $11.4 \%$ & $14.9 \%$ \\
\hline$A^{*} 26: 01$ & - & $5.5 \% \dagger$ & - & - & $7.1 \%$ & - \\
\hline$A^{\star} 30: 01$ & - & - & $7.6 \%$ & $8.1 \%$ & - & - \\
\hline
\end{tabular}




\begin{tabular}{|c|c|c|c|c|c|c|}
\hline$A * 30: 02$ & - & - & $6.7 \%$ & $8.1 \%$ & - & - \\
\hline$A^{*} 03: 01$ & $14.2 \%$ & $6.4 \%$ & $7.9 \%$ & $7.1 \%$ & $5.8 \%$ & - \\
\hline$A * 33: 03$ & - & $9.3 \%$ & $5.9 \%$ & $6.0 \%$ & $7.2 \%$ & $11.1 \%$ \\
\hline$A^{*} 68: 01$ & - & $6.7 \%$ & - & - & $7.4 \%$ & - \\
\hline$A^{*} 68: 02$ & - & - & $6.6 \%$ & $7.1 \%$ & - & - \\
\hline$A * 74: 01$ & - & - & $6.5 \%$ & $6.1 \%$ & - & - \\
\hline$B * 13: 01$ & - & - & - & - & - & $5.9 \%$ \\
\hline$B^{*} 15: 02$ & - & - & - & - & - & $6.3 \%$ \\
\hline$B * 15: 03$ & - & - & - & $5.4 \%$ & - & - \\
\hline$B * 35: 01$ & - & - & $6.6 \%$ & $6.8 \%$ & - & - \\
\hline$B * 35: 03$ & - & $5.6 \%$ & - & - & $5.3 \%$ & - \\
\hline$B * 40: 01$ & - & - & - & - & - & $13.7 \%$ \\
\hline$B * 42: 01$ & - & - & $5.9 \%$ & $6.4 \%$ & - & - \\
\hline$B * 44: 02$ & $12.1 \%$ & - & - & - & - & - \\
\hline$B * 44: 03$ & $5.6 \%$ & $6.1 \%$ & - & - & - & - \\
\hline$B * 46: 01$ & - & - & - & - & - & $13.4 \%$ \\
\hline$B^{\star} 51: 01$ & - & $7.7 \%$ & - & - & $9.1 \%$ & $5.1 \%$ \\
\hline$B^{\star} 52: 01$ & - & $7.2 \%$ & - & - & $7.4 \%$ & - \\
\hline$B * 53: 01$ & - & - & $13.0 \%$ & $14.4 \%$ & - & - \\
\hline$B * 57: 01$ & - & $5.2 \%$ & - & - & - & - \\
\hline$B * 58: 01$ & - & - & - & - & - & $9.3 \%$ \\
\hline$B^{\star} 07: 02$ & $17.8 \%$ & - & $6.8 \%$ & $6.2 \%$ & - & - \\
\hline $\mathrm{B}^{\star} 08: 01$ & $17.5 \%$ & $6.4 \%$ & - & - & $9.6 \%$ & - \\
\hline$C^{*} 01: 02$ & - & - & - & - & - & $20.1 \%$ \\
\hline$C^{*} 12: 02$ & - & $8.2 \%$ & - & - & $7.9 \%$ & - \\
\hline$C * 12: 03$ & - & $5.9 \%$ & - & - & $6.9 \%$ & - \\
\hline$C^{*} 15: 02$ & - & $10.4 \%$ & - & - & $10.3 \%$ & - \\
\hline$C^{*} 16: 01$ & - & - & $9.2 \%$ & $9.5 \%$ & - & - \\
\hline$C^{*} 17: 01$ & - & - & $7.1 \%$ & $8.1 \%$ & - & - \\
\hline$C^{\star} 03: 02$ & - & - & - & - & - & $9.4 \%$ \\
\hline$C^{\star} 03: 04$ & $5.4 \%$ & - & $5.1 \%$ & $5.1 \%$ & - & $10.5 \%$ \\
\hline$C^{*} 04: 01$ & $6.6 \%$ & $13.3 \%$ & $22.4 \%$ & $23.4 \%$ & $12.5 \%$ & - \\
\hline$C^{*} 05: 01$ & $12.0 \%$ & - & - & - & - & - \\
\hline$C^{*} 06: 02$ & $9.3 \%$ & $13.3 \%$ & $6.9 \%$ & $6.5 \%$ & $13.6 \%$ & - \\
\hline$C^{*} 07: 01$ & $20.3 \%$ & $9.4 \%$ & $12.1 \%$ & $11.5 \%$ & $8.1 \%$ & - \\
\hline$C^{*} 07: 02$ & $18.9 \%$ & $13.6 \%$ & $6.7 \%$ & $6.0 \%$ & $14.2 \%$ & $17.7 \%$ \\
\hline$C^{*} 08: 01$ & - & - & - & - & - & $10.6 \%$ \\
\hline $\mathrm{C}^{*} 08: 02$ & $5.7 \%$ & - & - & - & - & - \\
\hline DPA $1{ }^{*} 01: 03$ & $18.0 \%$ & $33.9 \%$ & $34.7 \%$ & $28.0 \%$ & $32.7 \%$ & $32.2 \%$ \\
\hline $\mathrm{DPA}^{*}{ }^{*} 02: 01$ & $14.3 \%$ & $24.6 \%$ & $32.6 \%$ & $32.7 \%$ & $24.7 \%$ & $9.0 \%$ \\
\hline $\mathrm{DPA}^{*} 02: 02$ & - & $8.2 \%$ & $18.7 \%$ & $22.3 \%$ & $6.8 \%$ & $45.1 \%$ \\
\hline DPA1*03:01 & - & - & $9.7 \%$ & $11.7 \%$ & - & - \\
\hline DPB1*01:01 & - & - & $33.5 \%$ & $37.9 \%+$ & - & - \\
\hline DPB1*13:01 & - & $6.2 \%$ & - & - & $5.6 \%$ & $5.6 \%$ \\
\hline DPB1*17:01 & - & - & $6.3 \%$ & $6.9 \%$ & - & - \\
\hline DPB1*18:01 & - & - & $5.4 \%$ & - & - & - \\
\hline DPB1*02:01 & $10.1 \%$ & $18.4 \%$ & $8.9 \%$ & $7.9 \%$ & $16.5 \%$ & $15.3 \%$ \\
\hline DPB1*02:02 & - & - & - & - & - & $6.3 \%$ \\
\hline DPB1*26:01 & - & $5.1 \%$ & - & - & $5.4 \%$ & - \\
\hline DPB1*03:01 & $9.5 \%$ & - & - & - & - & - \\
\hline $\mathrm{DPB}^{*} 04: 01$ & $47.2 \%$ & $36.0 \%$ & $8.2 \%$ & - & $38.1 \%$ & $8.1 \%$ \\
\hline DPB1*04:02 & $8.8 \%$ & $7.4 \%$ & $11.6 \%$ & $12.4 \%$ & $7.5 \%$ & - \\
\hline
\end{tabular}




\begin{tabular}{|c|c|c|c|c|c|c|}
\hline DPB1*05:01 & - & - & - & - & - & $40.4 \%$ \\
\hline DQA1*01:01 & $12.4 \%$ & $18.0 \%$ & $13.1 \%$ & $13.4 \%$ & $16.2 \%$ & $11.4 \%$ \\
\hline DQA1*01:02 & $23.4 \%$ & $9.9 \%$ & $30.4 \%$ & $30.1 \%$ & $9.2 \%$ & $17.5 \%$ \\
\hline DQA1*01:03 & - & $20.6 \%$ & - & - & $18.5 \%$ & $7.4 \%$ \\
\hline DQA1*02:01 & $15.7 \%$ & $15.0 \%$ & $10.4 \%$ & $8.9 \%$ & $14.6 \%$ & - \\
\hline DQA1*03:01 & $18.1 \%$ & $9.5 \%$ & $7.9 \%$ & $7.4 \%$ & $7.3 \%$ & $28.1 \%$ \\
\hline DQA1*04:01 & - & - & $11.6 \%$ & $12.8 \%$ & - & - \\
\hline DQA1*05:01 & $23.3 \%$ & $21.6 \% \dagger$ & $17.8 \%$ & $18.0 \%$ & $30.0 \%$ & $16.8 \%$ \\
\hline DQA1*06:01 & - & - & - & - & - & $10.2 \%$ \\
\hline DQB1*02:01 & $17.5 \%$ & $12.2 \%$ & $12.4 \%$ & $12.9 \%$ & $18.1 \%$ & $7.1 \%$ \\
\hline DQB1*02:02 & $9.6 \%+$ & $8.4 \%$ & - & - & $8.9 \%$ & - \\
\hline DQB1*03:01 & $15.4 \%$ & $13.0 \%$ & $16.9 \%$ & $16.9 \%$ & $13.9 \%+$ & $20.8 \%$ \\
\hline DQB1*03:02 & $8.5 \%$ & $7.9 \%$ & - & - & $5.9 \%$ & $6.3 \%$ \\
\hline DQB1*03:03 & $5.1 \%$ & $5.6 \%$ & - & - & $5.5 \%$ & $16.2 \%$ \\
\hline DQB1*04:01 & - & - & - & - & - & $5.4 \%$ \\
\hline DQB1*04:02 & - & - & $7.3 \%$ & $8.0 \%$ & - & - \\
\hline DQB1*05:01 & $10.9 \%$ & $9.8 \%$ & $14.3 \%$ & $15.0 \%$ & $8.9 \%$ & - \\
\hline DQB1*05:02 & - & - & - & - & - & $10.2 \%$ \\
\hline DQB1*05:03 & - & $8.6 \%$ & - & - & $7.3 \%$ & - \\
\hline DQB1*06:01 & - & $14.6 \%$ & $-\dagger$ & - & $12.8 \%$ & $10.9 \%$ \\
\hline DQB1*06:02 & $18.8 \%$ & - & $17.3 \%$ & $16.1 \%$ & - & - \\
\hline DQB1*06:03 & - & $6.8 \%$ & - & - & $6.3 \%$ & - \\
\hline DRB1*10:01 & - & $6.4 \%$ & - & - & $5.3 \%$ & - \\
\hline $\mathrm{DRB}^{*} 01: 01$ & $7.1 \%$ & - & - & - & - & - \\
\hline DRB1*01:02 & - & - & $5.1 \%$ & $5.7 \%$ & - & - \\
\hline DRB1*11:01 & - & $5.3 \%$ & $7.7 \%$ & $8.0 \%$ & $5.6 \%$ & - \\
\hline DRB1*12:02 & - & - & - & - & - & $10.6 \%$ \\
\hline DRB1*13:01 & - & $6.5 \%$ & - & $5.7 \%$ & $6.0 \%$ & - \\
\hline DRB1*13:02 & - & - & $6.5 \%$ & $7.0 \%$ & - & - \\
\hline DRB1*15:01 & $19.2 \%$ & $9.8 \%$ & - & - & $8.3 \%$ & $8.8 \%$ \\
\hline $\mathrm{DRB1}^{*} 15: 02$ & - & $10.1 \%$ & - & - & $9.5 \%$ & - \\
\hline $\mathrm{DRB1}^{*} 15: 03$ & - & - & $12.7 \%$ & $13.1 \%$ & - & - \\
\hline DRB1*03:01 & $17.5 \%$ & $11.6 \%$ & $6.4 \%$ & $6.6 \%$ & $17.7 \%$ & $7.2 \%$ \\
\hline DRB1*03:02 & - & - & $6.2 \%$ & $7.3 \%$ & - & - \\
\hline $\mathrm{DRB}^{*} 04: 01$ & $9.8 \%$ & - & - & - & - & - \\
\hline DRB1*04:05 & - & - & - & - & - & $6.0 \%$ \\
\hline DRB1*07:01 & $15.7 \%$ & $14.9 \%$ & $8.9 \%$ & $7.7 \%$ & $14.6 \%$ & - \\
\hline DRB1*08:03 & - & - & - & - & - & $6.2 \%$ \\
\hline DRB1*08:04 & - & $-\dagger$ & $6.5 \%$ & $7.0 \%$ & - & - \\
\hline DRB1*09:01 & - & - & - & - & - & $15.6 \%$ \\
\hline DRB3*01:01 & $19.5 \%$ & $5.8 \%$ & $13.4 \%$ & $14.5 \%$ & $5.1 \%$ & - \\
\hline $\mathrm{DRB3}^{* 02: 02}$ & $9.3 \%$ & $27.8 \% \dagger$ & $24.0 \%$ & $24.6 \%$ & $35.3 \%$ & $20.3 \%$ \\
\hline DRB3*03:01 & - & - & $9.4 \%$ & $10.1 \%$ & - & $11.6 \%$ \\
\hline DRB3 - no gene & $32.7 \%$ & $41.2 \%$ & $49.2 \%$ & $47.9 \%$ & $47.3 \%$ & $40.4 \%$ \\
\hline DRB4*01:01 & $9.1 \%$ & - & $8.4 \%$ & $8.0 \%$ & - & - \\
\hline DRB4*01:03 & $23.2 \%$ & $20.5 \%$ & - & - & $19.1 \%$ & $27.8 \%$ \\
\hline DRB4 - no gene & $33.7 \%$ & $24.9 \%$ & $16.2 \%$ & $14.7 \%$ & $22.5 \%$ & $34.2 \%$ \\
\hline DRB5*01:01 & $19.1 \%$ & $8.8 \%$ & $15.0 \%$ & $13.8 \%$ & $7.8 \%$ & $12.0 \%$ \\
\hline DRB5 - no gene & $19.6 \%$ & $11.7 \%$ & $17.5 \%$ & $16.7 \%$ & $11.4 \%$ & $14.3 \%$ \\
\hline $\begin{array}{l}\text { No. alleles } \\
\text { included in } \\
\text { analysis }\end{array}$ & 46 & 55 & 56 & 56 & 55 & 50 \\
\hline
\end{tabular}


- Allele had $<5 \%$ frequency among this ethnic group so was excluded from analysis $\dagger$ Allele was not in HWE in this ethnic group so was excluded from analysis

Table 3: summary of calculated eGFR values

\begin{tabular}{|l|l|l|l|l|}
\hline Ethnicity & $\begin{array}{l}\text { No. subjects with } \\
\text { eGFR based on } \\
\text { creatinine } \\
\text { calculated }\end{array}$ & $\begin{array}{l}\text { Average eGFR } \\
\text { based on } \\
\text { creatinine in } \\
\mathrm{mL} / \mathrm{min} / 1.73 \mathrm{~m}^{2} \\
(\mathrm{SD})\end{array}$ & $\begin{array}{l}\text { No. subjects with } \\
\text { eGFR based on } \\
\text { cystatin } \\
\text { calculated }\end{array}$ & $\begin{array}{l}\text { Average eGFR } \\
\text { based on cystatin } \\
\text { in } \mathrm{mL} / \mathrm{min}_{1} / 1.73 \mathrm{~m}^{2} \\
\text { (SD) }\end{array}$ \\
\hline Irish & 12,191 & $92.4(13.3)$ & 12,194 & $89.1(16.2)$ \\
\hline Indian & 5,475 & $94.6(14.4)$ & 5,475 & $84.5(18.4)$ \\
\hline Black Caribbean & 4,101 & $98.3(17.7)$ & 4,100 & $94.5(16.7)$ \\
\hline Black African & 3,038 & $102.0(18.1)$ & 3,041 & $96.1(16.8)$ \\
\hline Pakistani & 1,662 & $97.0(17.6)$ & 1,662 & $86.5(17.7)$ \\
\hline Chinese & 1,435 & $98.2(12.6)$ & 1,437 & $98.9(13.5)$ \\
\hline
\end{tabular}

Table 4: Alleles associated with renal function

\begin{tabular}{|c|c|c|c|c|c|c|c|c|}
\hline \multirow[t]{2}{*}{ HLA- } & \multirow[t]{2}{*}{ Freq } & \multirow{2}{*}{$\begin{array}{l}\text { Effect on } \\
\text { renal } \\
\text { function }\end{array}$} & \multicolumn{4}{|l|}{ eGFR } & \multicolumn{2}{|c|}{ CKD stage 2 or $\mathrm{u}$} \\
\hline & & & Based on & $\begin{array}{l}\text { Beta } \\
(\mathrm{mL} / \mathrm{min} / \\
\left.1.73 \mathrm{~m}^{2}\right)\end{array}$ & $P$ value & $\begin{array}{l}\text { Adjusted } \\
\mathrm{P} \text { value }\end{array}$ & $\begin{array}{l}\text { Odds } \\
\text { ratio }\end{array}$ & $P$ value \\
\hline \multicolumn{9}{|c|}{ Black African subjects $\left(\mathrm{P}<8.9 \times 10^{-4}\right)$} \\
\hline$B * 53: 01$ & $14.4 \%$ & Decrease & Creatinine & -2.628 & $8.38 \times 10^{-6}$ & $4.7 \times 10^{-4}$ & \multirow{6}{*}{\multicolumn{2}{|c|}{ Not significant }} \\
\hline$C^{*} 04: 01$ & $23.4 \%$ & Decrease & Creatinine & -1.667 & $4.80 \times 10^{-4}$ & 0.027 & & \\
\hline DRB1*03:01 & $6.6 \%$ & Increase & Creatinine & 3.2 & $7.13 \times 10^{-5}$ & 0.004 & & \\
\hline DPA1*01:03 & $28.0 \%$ & Increase & Creatinine & 2.276 & $4.13 \times 10^{-7}$ & $2.3 \times 10^{-5}$ & & \\
\hline DPA1*02:01 & $32.7 \%$ & Decrease & Creatinine & -1.569 & $3.25 \times 10^{-4}$ & 0.018 & & \\
\hline DPA1*02:02 & $22.3 \%$ & Decrease & Creatinine & -1.716 & $4.49 \times 10^{-4}$ & 0.025 & & \\
\hline \multicolumn{9}{|c|}{ Irish subjects $\left(\mathrm{P}<1.1 \times 10^{-3}\right)$} \\
\hline DRB1*04:01 & $9.8 \%$ & Increase & Cystatin & 1.075 & $3.01 \times 10^{-4}$ & 0.014 & 0.836 & $1.77 \times 10^{-}$ \\
\hline DRB4 - no gene & $33.7 \%$ & Increase & Cystatin & 0.619 & $8.62 \times 10^{-4}$ & 0.040 & \multicolumn{2}{|c|}{ Not significant } \\
\hline \multicolumn{9}{|c|}{ Indian subjects $\left(P<9.1 \times 10^{-4}\right)$} \\
\hline DRB1*03:01 & $11.6 \%$ & Decrease & Cystatin & -1.72 & $8.69 \times 10^{-5}$ & 0.005 & \multirow{3}{*}{\multicolumn{2}{|c|}{ Not significant }} \\
\hline DQB1*02:01 & $12.2 \%$ & Decrease & Cystatin & -1.755 & $4.11 \times 10^{-5}$ & 0.002 & & \\
\hline DRB3 - no gene & $41.2 \%$ & Decrease & Cystatin & -1.033 & $4.88 \times 10^{-4}$ & 0.027 & & \\
\hline
\end{tabular}

